\title{
IS IT POSSIBLE TO SEE DARKNESS? GOETHE AND ARISTOTLE ON THE ROLE OF LIGHT AND \\ DARKNESS IN VISION
}

\author{
SVETLANA MESYATS \\ RAS Institute of Philosophy (Moscow) \\ messiats@mail.ru
}

\begin{abstract}
J.W. Goethe in his Farbenlehre deduced all physical colors from a simple primordial phenomenon that takes place every time light and darkness act through a semitransparent colorless medium either on our eyes or on the opposite surfaces. This basic rule of Goethe's color theory was criticized by his contemporary physicists, who argued that darkness could not play an active role in the origin of colors because of being a mere absence of light. The paper demonstrates that this criticism became possible only if one shares the Newtonian view on the nature of light and darkness. Goethe however held a more traditional point of view, which he traced back to Antiquity and Aristotle. In contrast to Newton and his followers, previous scientists considered light not as an immediate cause of colors but as an actually transparent medium that conveyed colors from the visible objects to the organ of sight. For vision to take place, the color must first affect the light, which in its turn, must affect the faculty of vision. Though it is difficult to say what kind of change the light undergoes when some colored object is seen through it, most Aristotle commentators agree that this change must be real and not mere relational. In Aristotle's physics, however, things that are capable of acting on and being affected by one another are either contraries or consist of contraries. Therefore, to be visible the color must be either dark or to contain darkness. Thus, assuming that Goethe shared the Aristotelian concept of light, we have to conclude that he was not mistaken saying that darkness "acts" upon our eyes or "is seen through" the illuminated semi-transparent medium.
\end{abstract}

KEYWORDS: Goethe's Farbenlehre, apparent colors, primordial phenomenon, light and darkness, Aristotle's color theory, transparent medium, vision, acting and being affected.

The great German poet and writer Johann Wolfgang Goethe (1749-1832) is also known as an outstanding scientist and the author of an original theory of color that appears to be remarkably different from that of Isaac Newton. Goethe set

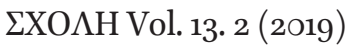

(C) Svetlana Mesyats, 2019

www.nsu.ru/classics/schole

DOI:10.25205/1995-4328-2019-13-2-537-553 
forth his doctrine of color in several writings, composed in a period between 1791 and 1830. The best known and the most important of them is his treatise Zur Farbenlehre, published in 1810. It is divided into three parts. The first, Didactic Part of the Farbenlehre (also known as Entwurf einer Farbenlehre, that is Project of color theory) presents Goethe's own views on color phenomena. The second, Polemical Part, contains a refutation of Newton's color theory. The third, Historical Part, provides materials for the history of color from Antiquity to the end of the $18^{\text {th }}$ century.

\section{The primordial phenomenon of all physical colors}

Goethe organized all color phenomena under three main headings of physiological, physical, and chemical colors. Physiological colors are those intrinsic colors that appear in the eye and belong to the subject of vision. Colors of bodies that exist outside us receive the name of chemical colors. In contrast of the first two, physical colors are both subjective and objective because of being produced in the eye by certain material colorless mediums, which may be either transparent or semi-transparent or altogether opaque, yet transmitting light. We see colors of this kind every time light reflects back from the surface of bodies (Goethe calls these colors "catoptrical"), or passes through a transparent colorless medium ("dioptrical colors"), or goes around body's edge ("paroptical"), or appear under different conditions on the colorless surfaces of bodies ("epoptical"). Colors of the rainbow and those visible on the soup films or the pigeon's neck belong to physical ones. The fleeting nature and amazing brightness of these colors, in Goethe's words, allowed former investigators to call them "colores apparentes," "fluxi," "phantastici," "falsi," "speciose" and "emphatici."

Goethe deduces physical colors from the simple elementary phenomenon that takes place every time light or darkness acts through a semi-transparent colorless medium either on the eye of the observer or on opposite surfaces. ${ }^{2}$ Light taken in itself, especially in its highest degree, such as the light of the sun, is blinding and colorless. The same light, however, seen through a very slightly turbid medium appears us yellow. If the density of the medium increases or its volume becomes greater, the light gradually assumes a yellow-red hue, which at last deepens to a ruby-color. ${ }^{3}$ That is why the sun seen high in the sky through the thin atmospheric vapors appears us yellow, whereas the same sun seen in the morning or in the evening through the denser layers of the atmosphere acquires a red hue. On the

\footnotetext{
${ }^{1}$ Goethe, FL I, 136. Transl. Eastlake 1840, 56-57.

${ }^{2}$ Goethe, FL I, 143 .

${ }^{3}$ Goethe, FL I, 15 O.
} 
other hand, if one sees darkness through a slightly turbid medium, which is itself illuminated by the day-light, the blue color appears. ${ }^{4}$ So the sky seems blue because the darkness of the infinite space is seen through the atmospheric vapors illuminated by the day-light. ${ }^{5}$ Goethe believes that both these simple phenomena taken together not only produce all the visible colors, which can be presented in the form of the so-called "color circle" consisting of three main pairs of opposite color-hues (fig.1), but also explain their origin. Yellow and orange (red-yellow), situated on the left side of the circle, present different degrees of the light damped by the turbid medium, whereas the colors on the right side - blue and violet (red-blue) - are produced by darkness seen through the semi-transparent medium illuminated by the day-light. When the density of the medium reaches a certain point, both sides join together in a "purpur," that is pure red color. Green, on the other hand, arises on the opposite side of the circle as a result of the mixture of blue and yellow. If one combines both processes into one, one receives the general law of all color phenomena: for a color to appear, it is necessary that the action of light or darkness be mediated by a semi-transparent, turbid medium. Goethe says, that in contrast to the laws of his contemporary physics, which replace a natural phenomenon with a set of "the abstract products of reason," this rule "is not revealed by words and hypotheses to the understanding merely, but by real phenomena to the senses." ${ }^{\prime 6}$ In other words, this rule is itself a phenomenon; that is why we can see it not only by means of our reason or intellect but also by our own eyes. Since such a phenomenon expresses the highest rule and law of nature and makes, therefore, the basis of more particular effects, Goethe calls it "Ur-phenomenon" that is "primordial," "elementary" phenomenon. In the Farbenlehre he tries to show, how the Ur-phenomenon of light and darkness mentioned above explains the nature of all physical colors and in particular those appearing by refraction.

\footnotetext{
${ }^{4}$ Goethe, FL I, 151.

${ }^{5}$ Goethe, FL I, 155.

${ }^{6}$ Goethe, FL I, 175 .
} 


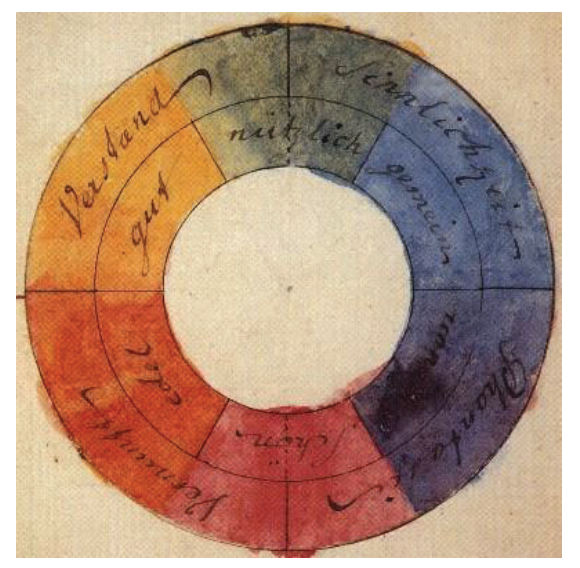

Figure 1. Goethe's six-hue color circle.

If we look through a prism at the objects around us, we see their central parts remain without change, whereas their edges colored in all the hues of a rainbow. If we look through the prism at one of the black-and-white tables placed by Goethe in his experimental apparatus, for example, on the black and white planes bordering each other, we see that the prismatic colors appear only on the border between black and white, dark and light. If we turn the table over, we see that the colors on the edge have changed, so instead of blue and violet, there appeared yellow and orange. If instead of monochrome planes one takes some image, for example, a white strip on a black background, then both sets of colors will be seen at once: yellow-red at one side of the strip and blue-violet at the other. If the strip is broad enough, then its center remains uncolored. However, if it narrows or moves away from the prism to a more considerable distance, then the expanded colored edges completely cover its surface, and the original white color of the image disappears. If one continues to move the image away from the prism, then the blue and yellow edges of the colored borders overlap, and green color appears in the middle of the image. As a result, one sees the familiar Newtonian spectrum, obtained by the English physicist in ${ }^{1672}$ during his famous experiment with a ray of light, which he first refracted by a prism and then converged in a shining point on a dark wall. ${ }^{7}$ Instead of a light point in Newton's experiment, Goethe used a white stripe on a black background, and this allowed him not only to simplify his experiment significantly but also to observe it in its development. He established that the color spectrum begins to appear at the opposite ends of the strip, where the white color of the strip borders on its black background. He saw that the green color, initially absent from the spectrum, appears as soon as the blue and yellow borders meet together in the center. Continuing to move the image away

\footnotetext{
${ }^{7}$ Turnbull 1959, 92.
} 
from the prism, he observed that the yellow and blue colors gradually disappear from the spectrum and entirely merge with each other into the green, so that there are only three colors remain at the end: red, green and purple.

In Goethe's opinion, such a successive consideration of the phenomenon in its development is the only way to get into its true essence. He believed that all the natural phenomena are not isolated separate things; they are continually developing processes with their beginning, culmination, and end. A separate fixed phenomenon is, as it were, a slice of such a process at a certain point of space and time; therefore, it can be explained only through the reference to the whole to which it belongs. To grasp this whole, one needs to conduct a series of experiments in which some basic conditions - such as the presence of a black-andwhite image, a prism, an observer - would remain unchanged, and the side conditions - such as the distance of the prism from the image, its refractive power, image size, and shape - would vary. By varying experimental conditions, the scientist can see the natural process in its full development and quickly determine what place this or that particular phenomenon occupies in it. ${ }^{8}$ On the contrary, an isolated experiment with strictly fixed experimental conditions doesn't allow him to find out what really happens in nature and forces, therefore, to invent some hypothetical theory that reduces the observed phenomenon to a set of the "abstract products of reason," such as the concepts of light rays, beams, waves, forces, etc. Goethe considered Newton's theory of color to be such a hypothetical abstract theory, built on a phenomenon artificially pulled out of its natural connections. He thought that the continuous spectrum with green color in the middle, appearing in Newtonian experimentum crucis, was a such a separated, partial phenomenon, derived from the more fundamental and general one, as a series of experiments with a white strip against a black background proved.

"We are convinced that natural science has committed a serious mistake (in the investigation of color phenomena) inasmuch as a secondary phenomenon has been placed higher in order - the primordial phenomenon has been degraded to an inferior place; the secondary phenomenon has been placed at the head, a compound effect has been treated as simple, a simple appearance as compound. Owing to this contradiction the most incredible complication and perplexity has been introduced in the physical inquiries." ${ }^{\prime \prime}$

To avoid this complication and explain physical colors correctly, one must deduce them not from the secondary, but from the primordial phenomenon, which,

\footnotetext{
${ }^{8}$ Ribe, Steinle 2002, 46 .

${ }^{9}$ Goethe, FL I, 176. Transl. Eastlake 1840, 73. On the controversy between Goethe and Newton see: Mesyats 2014, 313-317.
} 
according to Goethe, is the action of light and darkness mediated by a semitransparent or turbid medium. This phenomenon is not only the highest and the most general rule of nature but the foundation of the entire Goethe's color theory. Therefore, if it turns out to be wrong or based on an incorrect assumption, then the whole building of the Farbenlehre will collapse with it.

\section{Criticism of the primordial phenomenon}

Goethe formulates the primordial phenomenon of physical colors in sections 150 and 151 of his Farbenlehre as follows:

"The light seen through a very slightly turbid medium appears yellow to us."

"If on the other hand darkness is seen through a semi-transparent medium, which is itself illuminated by light striking on it, a blue color appears". ${ }^{10}$

Goethe's words about darkness puzzled most of his contemporary physicists and scientific reviewers of the Farbenlehre. ${ }^{11}$ How can darkness be visible, especially through the medium illuminated by light? Should we rather say that the observer sees the color caused by diffraction of light in the medium, and not the color of the dark background behind it? Furthermore: if darkness is merely the absence of light - "not-light," as Goethe defines it - how can its action on our eyes or external objects be as positive as the action of light? The questions raised by Goethe's contemporaries, seem to disprove his theory completely. However, let us not rush to conclusions and try to find the grounds that would allow us to save the primordial phenomenon of physical colors. In other words, let us try to answer the question, whether it is possible to see the darkness?

In the section on physiological colors, Goethe describes the action of darkness upon the organ of vision as follows:

"If we keep the eyes open in the totally dark place, a certain sense of privation is experienced. The organ is abandoned to itself. It retires into itself. That stimulating and grateful contact is wanting by means of which it is connected to the external world and becomes part of a whole."12

A little further while speaking about black color as a representative of darkness in bodies, Goethe says that "black leaves the eye in a state of repose."13 These words seem to suggest that the organ of vision can be put into action only by light, which means that the eye can see only when its retina is irritated. In a state of rest, the eye doesn't exercise its power of vision. Hence the certain sense of pri-

\footnotetext{
${ }^{10}$ Goethe, FL I, 151: "wird hingegen ... die Finsternis gesehen. “

${ }^{11}$ Wenzel 1991, 671.

${ }^{12}$ Goethe, FL I, 6.

${ }^{13}$ Goethe, FL I, 18.
} 
vation he is feeling in the completely dark place. In a dark room, we do not care whether to keep our eyes open or closed, because in either case, we cannot see anything. Nothing comes from the darkness to our eyes. So, it is reasonable to conclude that we perceive dark and black not as something positive, but rather through the absence of light and in contrast with it. For example, while considering a black square on a white background, we see, in fact, not the square itself, but its white border. If we remove the white background, we will find ourselves in a completely dark space and will not see anything, since no irritating action will come from the darkness into our eyes. The same happens if we put a turbid medium in between. As in the previous case, the darkness will leave our eyes in a state of rest, so that we will not see anything. Goethe nevertheless says again and again that the darkness "acts through" (hindurchwirkt) the illuminated turbid medium both on our eyes and on the opposite surface so that its action appears to be not only subjective but also objective. The mediated action of darkness makes us feel blue and leaves a reflection of blue color on the white screen in the camera obscura. ${ }^{14}$ By comparing the different passage of the Farbenlehre, one could conclude that in Goethe's view, darkness is both visible and invisible: it leaves the eye in a state of repose and at the same time acts on it through a turbid medium. However, before blaming the author of the Farbenlehre for this apparent contradiction, let us first try to find out, what did he think the darkness is.

Goethe defines darkness as "not-light." However, he does not explain what exactly this means. Whether darkness is a mere absence of light - "privative nothing without any characteristic" as Karl Mollweide, one of Goethe's contemporaries and critiques supposed $?^{15}$ Or is it a certain positive substance, opposing to light and acting against it, as Rudolf Steiner and his school believed ${ }^{26}$ In my opinion, to understand Goethe's concept of darkness, one needs first to find out, what does he think about the nature of light. Unfortunately, the Didactic Part of the Farbenlehre is not very helpful in this respect because just at the beginning of the treatise the author declares as useless "any attempt to express the nature of light abstractedly" and calls his readers instead to study colors as the active and passive modifications of light. ${ }^{17}$ However, in the Polemical and Historical Parts of the same work, Goethe makes it clear that his understanding of the light's nature substantially differs from that of contemporary physics. He admits his commitment to a more traditional and sound point of view, shared by most philosophers and physicists before Newton. In the Afterword to the Polemical Part and some

\footnotetext{
${ }^{14}$ Goethe, FL I, 143, $15^{2}$.

${ }^{15}$ Wenzel 1991, 671.

${ }^{16}$ Steiner $R$. Goethe als Denker und Forscher, in VFG, Bd. I, S. 38; Proskauer 1985, 45-46.

${ }^{17}$ Goethe, FL I, Vorwort: "Die Farben sind Taten des Lichtes, Taten und Leiden”.
} 
other texts on color theory, he summarizes this view as follows. (1) Light is the most simple, indivisible and homogenous entity we know. It is not a body, but rather a property (state, condition) of a certain substance. It doesn't consist of different parts or rays, that can be dispersed, compressed, accelerated or slowed down. Moreover, it doesn't consist of rays of different colors, because every colored light is darker than the colorless one. (2) Light is not the only source of color, but rather a condition of its appearance. ${ }^{18}$ Different colors arise not from the light itself, but from the mixture of light and shadow, black and white. In Goethe's own words: "Light and Darkness, brightness and obscurity, or if a more general expression is preferred, Light and Not-Light are necessary to the production of color."19 In the Historical Part of the Farbenlehre Goethe traces this view back to Antiquity and Aristotle, under whose name, he says, "we can collect all that the ancients knew about the subject." ${ }^{20}$ In particular, Aristotle perfectly understood that colors were not inherent in the light, but arose from a mixture of light and darkness, white and black. Though he could not accurately explain the way the different colors emerge, he was nevertheless well aware of the role of the semi-transparent or turbid medium in creating blue, yellow and red. ${ }^{21} \mathrm{He}$ attached great importance to the transparent as the medium of vision and considered light to be not a body, but a sort of accidental characteristic belonging to air, water, ether, and some solid substances. Aristotle's doctrine of light and color was shared by most European thinkers throughout the Middle Ages and the Renaissance until the growing opposition to his physics did not force the leading scientists of the $17^{\text {th }}$ century to develop a completely different concept of light. Newton and his followers regarded light not as something derivative, but as primordial, existing in itself, independent and unconditioned material substance, which like any ordinary body, has different parts and despite its apparent simplicity and unity, can be seen as something complex and heterogeneous. ${ }^{22}$

Since Goethe, as we have seen, adhered to the traditional Aristotelian concept of light, considering it authoritative and undeservedly forgotten after Newton, we should take a closer look at this doctrine, in the hope that it will help us answer the question of how dark and black act upon our eyes in vision.

\footnotetext{
${ }^{18}$ Guerlac 1986, 3 .

${ }^{19}$ Goethe, FL I, Einleitung: "Zur Erzeugung der Farbe Licht und Finsternis, Helles und Dunkles, oder, wenn man sich einer allgemeineren Formel bedienen will, Licht und Nichtlicht gefordert werde."

${ }^{20}$ Goethe, FL III, 327-328.

${ }^{21}$ Ibid.

${ }^{22}$ Goethe, FL III, 447-448.
} 


\section{Aristotle on the role of light in vision}

Since nothing can be visible without light, Aristotle considers it to be the essential condition of vision. ${ }^{23}$ Light is not a body, nor a movement of a body, nor an emanation from a body of any kind. It is an intrinsic characteristic of the air, water and many solid substances because of their ability to allow external objects to be visible through them. Aristotle calls this characteristic "transparency"

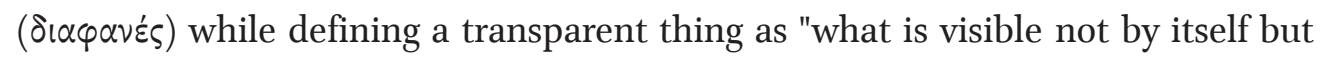
owing to the color of something else. ${ }^{24}$ Transparency is not a constant property of bodies, which is peculiar to them as far as they are air, water, glass and so on. It is some nature or potency ( $\delta \dot{v} v \alpha \mu \varsigma$ ) which they share with the eternal celestial body and which they can exercise in the present of fire or something like this. ${ }^{25}$ As long as the sun shines, the air remains transparent, but as soon as the sun disappears, it immediately grows dark and does not permit anything to be seen through. This does not mean, of course, that the air completely loses its transparency. Rather, it changes from actually to potentially transparent, that is from being illuminated to being dark. This example shows that which is light can also be dark. So, the light can be seen as the actuality and the darkness as the potentiality of the transparent. In Aristotle's words:

"Light is the actuality ( $\varepsilon^{2} \varepsilon \varepsilon^{\prime} \gamma \varepsilon \ltimes \alpha$ ) of the transparent qua transparent; and wherever transparency is potentially present, darkness is present too. Light is a sort of color

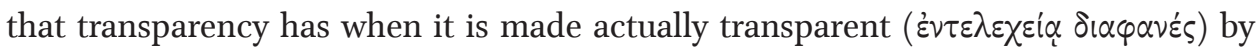
fire or something such as the celestial body, which has something in common with fire". ${ }^{26}$

By the acquaintance with Aristotle's theory of light, the most challenging thing is to set aside the usual view of light as a beam of rays emitted by some source of radiation and moving through space at an extremely high speed. Aristotle's concept of light has nothing similar to this. He criticizes Empedocles and Plato for considering light as moving, arguing that if this were so, then the movement of light at the sunrise over the distance from east to west couldn't escape our notice. ${ }^{27}$ In Aristotle' view light is not a kind of radiation, but a certain state or disposition $(\xi \xi \xi \zeta)$ of the air or any other transparent body, in which it instantly pass-

${ }^{23}$ Aristotle, De anima II, 418b 5: Since color is something visible and nothing can be visible without light, "we must explain in the first place what light is."

${ }^{24}$ De anima II, 7, 418b 4-6. Transl. by D. Ross: Ross 1961, 240.

${ }^{25}$ Aristotle, De sensu 439a 23-25.

${ }^{26}$ De anima II, 7, 418b 9-13.

${ }^{27}$ De anima II, 7. 418b 20-25. 
es as soon as the sun or some fiery body appears in it. $^{28}$ Though light is the essential condition of vision, it isn't itself visible. The sight certainly discerns light and distinguishes it from darkness, but this is not vision in the strict sense of the word. ${ }^{29}$ According to Aristotle, a vision like any other sensation consists of being moved and acted upon. ${ }^{30}$ He holds it to be some qualitative change or alteration $\left(\alpha \lambda \lambda 0^{\prime} \omega \sigma / \varsigma\right)$ produced in the organ of vision by a visible object. ${ }^{31}$ Every qualitative change involves the replacement of one quality by another, or rather the transition from the absence of some form to its possession. Sense perception takes place when the organ of sense, acted upon by a corresponding sensible object, is assimilated to it by acquiring its form and becoming its new matter. The perceiver is potentially what the sense object is actually, so by perceiving it is assimilated to the corresponding object and alters to become actually warm or red..$^{32}$ Thus, our ears hear because the air in them sounds in unison with the sound outside. Our skin feels warmth because of itself being warmed and our eyes as well see because of taking on colors of the surrounding objects. Light, on the contrary, cannot produce such an alteration in the organ of vision. The only form it is capable of imparting to the eye is the form of transparency. The eye, however, has this form already because of consisting of water. ${ }^{33}$ Therefore, when it is acted upon by light, it merely comes from the inactive possession of transparency to its active exercise. Such a transition from potential to actual state differs from an ordinary alteration. Aristotle says that it is "either not an alteration at all or a unique kind of alteration" that consists more in "preservation of something potential by something actual which is like it" than in the destruction of something by its contrary. It is rather "a development of something into its real self," or "a realization of something's nature" than assimilation to an external object by receiving its form. ${ }^{34}$ Aristotle uses the following example to illustrate this unique kind of alteration:

"When somebody who merely possesses knowledge comes to exercise it, then this process is either not an alteration at all... or else a unique kind of alteration. So, it is

\footnotetext{
${ }^{28}$ Ross 1995, 139 .

${ }^{29}$ Aristotle. De anima II, 10, 422a $20-23$.

${ }^{30}$ De anima II, 7, 419a 17-19: «for vision occurs when the sensitive faculty is acted upon.»

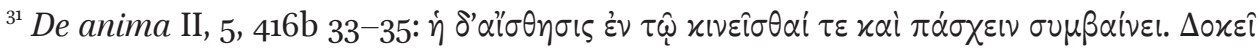

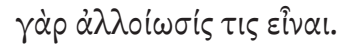

${ }^{32}$ Burnyeat 2002, 45 .

${ }^{33}$ Aristotle. De sensu II, 438b 5-16. See also: Alexander, In De sensu 35,17-36,4.

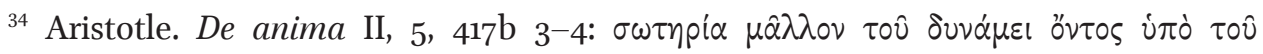

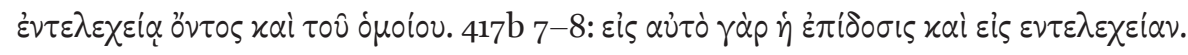


not sound to describe the thinker as being altered when he thinks, any more than it is true to say that the builder is altered when he builds." ${ }^{35}$

It is easy to see that the alteration produced by light in the organ of vision is not an ordinary one. Being affected by light and assimilated to it, the eye merely actualizes what it potentially is. As a result, its apprehension of light cannot be called perception and seeing in the strict sense of the word. The eye does not see the light because of receiving it not as something alien to itself, but as the actuality of its own form of transparency.

But the role of light in vision does not confine itself to the mere actualization of the organ of sight. Vision requires light also because it requires a medium. Aristotle considers it impossible to explain sense-perception by the purely mechanical action of one body on another. In contrast to Democritus, Empedocles and to some extent Plato he says that there is no vision, hearing or smell by direct contact of the organ of sense and the sense-object. In his own words: "if one places something that has color upon the eye itself, it will not be seen". ${ }^{6}$ Nothing that touches the organ of sense can produce a sensation. For seeing to take place, the colored object must first act on the actually transparent medium, which in turn must affect the faculty of sight. For this reason, Aristotle defines the proper object of vision, color, as "that which is capable of moving the actually transparent." ${ }^{37}$

The most obscure in this definition is the expression "capable of movement"

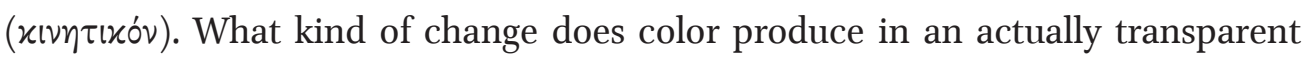
medium? Does it provoke its spatial movement or effect some other kind of change? This question caused many difficulties for all Aristotle commentators and scholars from Alexander of Aphrodisias and John Philoponus to Richard Sorabji and Myles Burnyeat. ${ }^{38}$ It is quite clear that color cannot cause spatial movement in a transparent medium because of reaching the eye immediately, while locomotion takes time. As follows, it must produce in it a sort of alteration or qualitative change ( $\alpha \lambda \lambda$ oi $\omega \sigma \varsigma)$. There are indeed several places in Aristotle where he calls change produced by a color in the actually transparent medium $\dot{\alpha} \lambda \lambda_{0} \omega_{\omega \sigma \iota \varsigma^{39}}$ But what kind of alteration does he mean? How does medium change, when some colored object is seen through it? In De Anima II, 7 Aristotle

\footnotetext{
${ }^{35}$ De anima II, 5, 417b 5-9.

${ }^{36}$ De anima II, 11, 419a12-13.

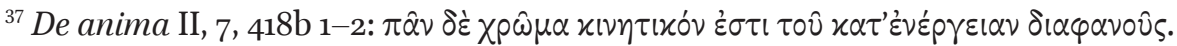

${ }^{38}$ See, for example, a discussion between R. Sorabji and M. Burnyeat in Sorabji 1995, 195-227; Burnyeat 1995 .

${ }^{39}$ Aristotle, De sensu 6, 446b 28-447a 12, and De anima III, 12, 434b 27 - 435a 3.
} 
says, that since the transparent is colorless, it is capable of receiving colors. ${ }^{40}$ This probably means that the transparent medium mediates by itself becoming colored, so that "what sight perceives directly is the color of the medium and only indirectly the color of the sensible object". ${ }^{41}$ Aristotle's words in De sensu 3 that "air and water obviously receive color," and that "the same transparent nature which inheres in the solid bodies, "also exhibits color outside them" ${ }^{42}$ seem to confirm this conclusion. However, the supposed coloration of the transparent medium entails some unsolvable difficulties, the most obvious of which was pointed out already by Alexander of Aphrodisias. In his commentary on Aristotle's De anima, Alexander noted that if the air between us and the colored object becomes itself colored, then it will no longer be transparent and not allow something else to be visible through it. But as everybody can see from their everyday experience, nothing prevents two different people from simultaneously seeing black and white objects through one and the same air. ${ }^{43}$ The literal coloration of the transparent medium seems to involve even more difficulties listed by Thomas Johansen in his book Aristotle on the sense-organs. Here are some of them:

(1) "If the medium itself had a color, then we would be unable to see it for the medium stretches up to the eye and we cannot see something that is put directly upon the eye."

(2) "If the medium becomes colored, then it will no longer be transparent in such a way that something else can be seen through it. The medium would itself become an object of vision. However, if so, it would no longer be a medium...

(3) If the medium received color during sense-perception, it would no longer be colorless and lose its ability to receive another color. So, there would be no alteration. $^{\text {"44 }}$

All these facts clearly show that the transparent medium cannot be affected by the colored object by itself becoming colored. As a result, we come back to the initial question of what kind of motion the color produces in the actually transparent medium so that the latter affects the organ of sight. According to some scholars, the medium does not undergo any real alteration. R. Sorabji denies it is being colored insisting however that the eye jelly takes on the color of the visible

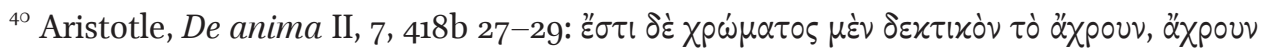

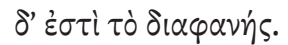

${ }^{41}$ Johansen 1997, 119.

${ }^{42}$ Aristotle, De sensu 3, 439a 35 - 439b2.

${ }^{43}$ Alexander, In De anima 62, 7-13. See also: Caston 2011, 153-154.

${ }^{44}$ Johansen 1997, 118-119.
} 
object. ${ }^{45}$ There is a view that the medium undergoes so-called "Cambridge" or relational change. According to M. Burnyeat, when some colored object appears to the observer through the medium, the later remains the same: it neither becomes colored nor moves nor increases or diminishes. The only change it undergoes is that the observer begins to see something through it. In other words, the medium changes only insofar as it comes in between the colored object and the organ of sight, which means that it undergoes not a real but only a relational change ${ }^{46} \mathrm{Th}$. Johansen argues against Burnyeat's account by pointing out that in Aristotle's philosophy, there is no change in the category of relation. His own solution of the problem implies that the medium goes colored not in an ordinary way. While transferring color from the colored object to the organ of sight, it undergoes socalled "quasi-coloration" or "apparent-coloration." It takes on the color of the visible object "only insofar as it makes the color accessible to the eye by allowing it to appear through it." ${ }^{m 7}$ The similar account of mediation can be found already in the ancient Aristotle commentators, in particular, in Alexander of Aphrodisias' treatise On the Soul. Alexander agrees that the actually transparent medium is affected by the colored object by getting itself colored, though this effect in most cases is not visible for us. The medium does not lose its transparency and ability to transmit colors because of undergoing not an ordinary but the so-called "positional" coloration ( $\varkappa \alpha \tau \dot{\alpha} \sigma \chi \dot{\varepsilon} \sigma(v) .{ }^{48}$ It does not take on color in the way that matter takes on a form. The color appears in the actually transparent medium in the same way as reflections come to be present in mirrors - due to the mere presence of the colored object and the particular position of the medium in relation to it. ${ }^{49}$ This means that the colored object effects in the medium a sort of shine or brilliance ( $\alpha \dot{\gamma} \gamma$ ') that bears a hue of the object's color. Air, water and other transparent bodies begin so to say to beam with colors of their surroundings. Alexander describes this effect as follows:

"For it is clear that light and transparent materials ... are changed in a certain way by colors, from the fact that in many cases when colors are seen through the light, one sees the light come to be the same color and carry the color along with. For it itself appears golden from the presence of gold, purplish from murex dye and greenish from foliage. Often one can see facing walls or the ground to be this sort of color, as though they were tinged with the color of these things, or even people, if they happen

\footnotetext{
${ }^{45}$ Sorabji 2001, 54 .

${ }^{46}$ Burnyeat 1995, 411.

${ }^{47}$ Johansen 1997, 120.

${ }^{48}$ Alexander, In De sensu 42, 27-43,1; 47,4; 50, 16-22; In De anima 61, 3 o.

${ }^{49}$ Alexander, In De anima 43, 2-4.
} 
to be standing nearby, because the illuminated medium relays this particular type of color from one set of things to the other by being modified." ${ }^{\prime \circ}$

\section{Is it possible to see darkness?}

Though the transparent medium undergoes only an "apparent" or "positional" coloration, which is obviously not an ordinary way of being colored, the most Aristotle interpreters agree that the change caused in it by the colored object must be nevertheless real and not mere relational. The medium must be somehow "moved" or affected by color, even though it is difficult to say what exactly this means. For the present paper, however, it is not very important to find out the exact way of the transparent medium' alteration. It is enough to know that it can be changed and affected by color in principle. But what does it mean to be affected and changed by something according to Aristotle? What happens when an agent acts on a patient and makes the latter change its quality? To answer this question, we need to bear in mind what Aristotle says about "acting" ( $\pi \circ \varepsilon i v)$ and "being affected" ( $\pi \dot{\alpha} \sigma \chi \varepsilon เ \nu)$ in De generatione et corruptione I, 7. He says that for one thing can act and the other being affected both must be either contraries or consist of contraries..$^{51}$ The like cannot be affected by like because in this case, it will also be capable of being affected by itself; and if this were so there would be nothing imperishable and immovable. The same is true for entirely different things. They also cannot affect each other, like whiteness, for example, could not be altered in any way by a line, or a line by whiteness. For alteration to take place, the agent and the patient should be alike in one respect and unlike in the other..$^{22}$ They must be the same in genus and contrary in species, as for example, white and black colors, straight and the curve lines, hot and cold bodies and so on. In Aristotle's own words,

"And, since patient and agent are the same and like in genus but unlike in species, and it is contraries that are like this, clearly the things that are capable of acting on and being affected by one another are the contraries and the intermediates. ${ }^{n 3}$

Since all things can change only in what they were not before, it is natural that every change implies a transition into the contrary or an intermediate. Moreover, since agent and patient are contraries, then when one affects the other, it is necessary that the agent changes the patient into itself. So the nature of every quali-

\footnotetext{
${ }^{50}$ Alexander, In De anima 42, 13-19. Slightly changed translation of V. Caston: Caston 2012,67 .

${ }^{51}$ Aristotle, GC. I, 7, 323b 26-27.

${ }^{5}$ GC I, 7, 323b 33-35.

${ }^{53}$ GC I, 7, 324a 4-7. Transl. by C.F.J. Williams.
} 
tative change consists in the assimilation of the patient to the agent, when "what is active makes what is passive like itself. ${ }^{n 4}$ When a fire hits, it makes a cold thing like itself by making it warmer than it was before. Consequently, when the cold thing cools, it assimilates the warm thing to itself by making it colder. The same should have a place when the color of the visible object affects the medium of vision. To produce a sort of qualitative change in the actually transparent, the color should be either contrary to it or contain a contrary. Now, the actuality of the transparent is light. Therefore, to affect light, the color must be either contrary to it or from the contrary. But the contrary of light is darkness. So to be able to act upon the actually transparent medium, the color should participate in darkness, that is, contain in itself something obscure and shadowy. For if light has to be affected in order to transmit colors from the visible object to the organ of sight, one needs not-light to affect it. No matter how bright a particular color may be, it must be darker than light to produce a sort of qualitative change or "movement" in it. The same goes for the eye. Since the organ of sight is transparent as consisting of water, it also can be affected and changed by the visible object only insofar as the latter contains dark and black. It would not be an overstatement to say that we see just because the inner light of our eyes is damped and obscured by the darkness of the external objects. The more this inner light is obscured, the darker colors we see, until the eye's transparency is completely replaced by darkness and we see black. All colors are visible as far as they contain a certain degree of dark and black, which permit them to affect our organ of vision. This is the reason why Aristotle, as well as Goethe, believes every color to be a mixture of white and black, light and dark, or to use a more general expression, of Light and NotLight..$^{55}$

Now, going back to our initial question of whether darkness is visible, we have to conclude that from the viewpoint of Aristotle's theory of light and color, it undoubtedly is. Darkness is visible because as a light's contrary, it necessarily affects the actually transparent medium both within our eyes and outside them. Thus, everybody who shares the Aristotelian concept of light would not mistake when saying that darkness "acts" upon our eyes or "is seen through" the illuminated semi-transparent medium. So, if Goethe's views on light and darkness were indeed in many respects similar to that of Aristotle, then the criticism of his primordial phenomenon does not reach the goal. The author of the Farbenlehre obviously was not mistaken when deducing the origin of all physical colors from the simple phenomenon of light and darkness acting through a semi-transparent illuminated medium either upon our eyes or on the opposite surfaces.

\footnotetext{
${ }^{54}$ GC I, 7, 324a 10-11.

${ }^{55}$ Aristotle, De sensu 3, 419b25-27.
} 


\section{ABBREVIATIONS}

De anima - Aristotle, De anima, ed. D. Ross. Oxford: University Press, 1961.

De sensu - Aristotle, "De sensu et sensibilibus", Aristotle. Parva naturalia, ed. D. Ross. Oxford: Clarendon Press, 1955.

GC - Aristotle, De generatione et corruptione, transl. C. J. F. Williams, Oxford: Clarendon Press, 1982.

FL I - Goethe, Zur Farbenlehre. Didaktischer Teil, hrsg. R. Matthaei und D. Kuhn, LA I 4. Weimar: Hermann Böhlaus Nachfolger, 1973

FL II - Goethe, Zur Farbenlehre. Polemischer Teil, hrsg. R. Matthaei, LA I 5. Weimar: Hermann Böhlaus Nachfolger, 1958.

FL III - Goethe, Zur Farbenlehre. Historischer Teil, hrsg. D. Kuhn und K. L. Wolf, LA I 6. Weimar: Hermann Bohlhaus Nachfolger, 1959.

LA - Leopoldina Ausgabe

\section{REFERENCES}

Burnyeat, M. (1995) "How much happens when Aristotle sees red and hears middle C?" M.C. Nussbaum, A. Rorty, eds. Essays on Aristotle's "De Anima." Oxford: Clarendon Press, 421-434.

Burnyeat, M. (2002) “De Anima II, 5," Phronesis XLVIII, 28-88.

Eastlake, Ch. L., transl. (1840) Goethe's Theory of colors. London: John Murray.

Caston, V., transl. (2012) Alexander of Aphrodisias. On the Soul. Part I. London, New York: Bloomsbury.

Guerlac, H. (1986) "Can there be colors in the Dark? Physical Color Theory before Newton," Journal of the History of Ideas, 3-20.

Hett, W. S. transl. (1936) Aristotle. On the Soul, Parva naturalia, On Breath. London: Harvard University Press.

Johansen, T. K. (1997) Aristotle on the sense-organs. Cambridge: Cambridge University Press.

Matthaei, R., Hrsg. (1958) J.W. Goethe. Zur Farbenlehre. Historischer Teil, LA I, 5. Weimar: Hermann Bohlhaus Nachfolger.

Mesyats, S.V. (2014) "Goethe i Newton. Spor o cvete". M.S. Petrova, red., Intellektual'nye tradicii v proshlom i nastoyashchem. Moscow: Akvilon, 299-339 [Месяц, С.В. (2014) «Гёте и Ньютон. Спор о цвете», М.С. Петрова, ред., Интеллектуальные традииии в прошлом и настоящем, Москва: Аквилон, 299-339].

Ott, G. und Proskauer, H.O., hrsg. (1979) J.W Goethe. Farbenlehre. Mit Einleitungen und Kommentaren von RudolfSteiner, Bd. I-III. Stuttgart: VFG.

Proskauer, H. O. (1985) Zum Studium von Goethes Farbenlehre. Basel: Zbinden Verlag.

Ribe, N. and Steinle, F. (2002) "Exploratory Experimentation: Goethe, Land and Color Theory," Physics today 55, 43-47.

Ross, D., ed. (1955) Aristotle. Parva naturalia. Oxford: Clarendon Press.

Ross, D., ed. (1961) Aristoteles. De anima. Oxford: University Press.

Ross, D. (1995) Aristotle. London: Routledge. 
Sorabji, R. (1995) "Intentionality and Physiological Processes: Aristotle's theory of sense perception," M.C. Nussbaum, A. Rorty, eds. Essays on Aristotle's "De Anima”. Oxford: Clarendon Press, 195-227.

Sorabji, R. (2001) "Aristotle on Sensory Processes and Intentionality. A Replay to Myles Burnyeat,” D. Perler, ed. Ancient and Medieval Theories of Intentionality. Leiden: Brill, 49-61.

Steiner, R. (1979) "Goethe als Denker und Forscher", G. Ott and H. O. Proskauer, hrsg. J.W. Goethe. Farbenlehre. Mit Einleitungen und Kommentaren von Rudolf Steiner, Bd. I. Stuttgart: VFG.

Towey, A., transl. (2000) Alexander of Aphrodisias. On Aristotle's “On Sense Peception". Ithaca, New-York: Cornell University Press.

Turnbull, H. W., ed. (1959) Newton. Correspondence of Isaac Newton, v. I. Cambridge: Cambridge University Press.

Wendland, P., ed. (1910)Alexandri Aphrodisiensis In Aristoteles De sensu commentaria, CAG, Bd. 3.1, Berlin: Reimer.

Wenzel, M., Hrsg. (1991) J.W. Goethe. Schriften zur Farbenlehre 1790-1807, Bd. XXIII / 2. Frankfurt am Mein: DKV.

Williams, C. J. F., transl. (1982) Aristotle's De generatione et corruptione. Oxford: Clarendon Press. 